\title{
A MÚSICA COMO COADJUVANTE NA METODOLOGIA DE ENSINO NA EDUCAÇÃO INFANTIL
}

\author{
MUSIC AS AN ADJUNCT TO THE TEACHING METHODOLOGY IN EARLY CHILDHOOD \\ EDUCATION
}

\author{
Cleidiane Tebas Viana Alves \\ Prefeitura Municipal de Ibitirama, Espírito Santo, ES, Brasil. E-mail: cleiditebas@gmail.com
}

DOI: https://doi.org/10.46550/amormundi.v2i7.130

Recebido em: 14.10.2021

Aceito em: 28.11.2021

\begin{abstract}
Resumo: A designação da música na educação Infantil faculta incondicionalmente inúmeras oportunidades para que a criança consiga de forma prazerosa aprimorar suas habilidades motoras, controlando seus músculos e aprendendo a mover-se com maestria. Formando assim aos poucos A sua identidade, percebendo-se diferente e ao mesmo tempo parte integrante do outro. Ao contato com a música, seus conhecimentos são ampliados envolvendo ainda a expansão de suas sensibilidades para consigo mesmo e o outro, oportunizando a descoberta do mundo a sua volta, suas interaçóes sociais envolta a esse meio serão marcadas para sempre com boas experiências. A música ainda no contexto da educação envolve outras áreas de aprendizagem, facilitando e cooperando na aprendizagem dessas de forma prazerosa, através principalmente da autoestima, tendo em vista essas contribuiçóes a musicalização torna-se uma aliada importante no crescimento do universo que liga expressão de sentimento, ideia, valores, crenças, entre outras, auxiliando de forma de forma continua a comunicação com o mundo externo.
\end{abstract}

Palavras-chave: Música; Educação; Criança; Pedagogia.

Abstract: The assignment of music in early childhood education unconditionally provides countless opportunities for the child to improve his motor skills in a pleasurable way, controlling his muscles and learning to move with mastery. Thus, gradually forming his identity, realizing that he is different and, at the same time, an integral part of others. When in contact with music, their knowledge is expanded, involving the expansion of their sensitivities towards themselves and others, providing an opportunity to discover the world around them; their social interactions in this environment will be forever marked with good experiences. Music in the context of education also involves other areas of learning, facilitating and cooperating in the learning of these in a pleasurable way, mainly through self-esteem. In view of these contributions, musicalization becomes an important ally in the growth of the universe that connects expression of feelings, ideas, values, beliefs, among others, helping to continuously communicate with the outside world.

Keywords: Music; Education; Child; Pedagogy. 


\section{Introduçáo}

耳se estudo tem como principal objetivo apresentar as contribuiçóes na educação

Cinfantil. Nessa perspectiva, pode-se dizer que a música está inserida na história da humanidade, da antiguidade aos dias atuais, exercendo diferentes funçôes em todas as regiôes do globo terrestre, nas variadas culturas e em todas as épocas, podendo assim ser considerada por alguns como uma linguagem universal, a qual ultrapassa barreiras do tempo e do espaço.

Nesse sentido, destacamos que a cantiga faz parte da vida das crianças, de algumas até mesmo antes do nascimento e essa relação criada entre a melodia e indivíduo traz consigo contribuiçôes extraordinárias no decorrer da infância a caminho de todo o sempre.

Evidenciamos que modilho muitas é vezes usado com desprendimentos em brincadeiras infantis serve como forma de expressão, relação social, estabelecimentos de regras, gerando muita aprendizagem e claro, diversão, isso é apenas um reflexo da grande importância da música na educação infantil.

Apesar do grande valor que atribui ao desenvolvimento cognitivo, social e afetivo da criança muitas vezes o papel representativo da ciranda é de pouca relevância dentro do contexto da escola e sobre isso, Loureiro nos diz que, "O aprendizado de música deve ser um ato de desprendimento prazeroso, que comungue com as experiências da criança sem ser imposição ou que busque a qualquer custo que a criança domine um instrumento, o qual pode minar sua sensibilidade e criatividade".

Esse estudo justifica-se considerando a importância em compreender a música, bem como suas contribuiçôes no que diz respeito à educação infantil.

Em reverência ao exposto, o grande propósito aqui é a compreensão da música na educação infantil como colaboradora no desenvolvimento integral da criança. Nesse sentido, visando facilitar a compreensão do tema abordado, organizou-se esse estudo da seguinte maneira: primeiramente apresentamos uma breve panorâmica da música no Brasil, em seguida a Música e educação infantil, na sequência aborda o processo do trabalho musical na educação infantil e, por fim, as consideraçóes finais.

\section{Breve panorâmica da música no Brasil}

A música no Brasil tem suas origens a partir de um conjunto formado por elementos europeus, portugueses que aqui colonizaram como os padres jesuítas que, usavam suas músicas afim de atrair atençáo em seus cultos, que por sua vez são as primeiras manifestaçóes musicais registradas em solos brasileiros, os africanos, escravos trazidos pelos portugueses afim de auxílio na colonização e indígenas, devido aos índios nativos no país, isso gerou uma enorme variedade de estilos musicais enriquecendo de forma extraordinária a música no Brasil.

França (1953, p. 7), em sua obra "Música no Brasil" nos mostra esse contexto:

O coral Gregoriano mágico instrumento de conversão de que se utilizou o jesuíta José de Anchieta, aquela magnífica figura de evangelizador. E com ele os jesuítas Aspicuelta Navarro e Manuel de Nóbrega. Este dizia que: "com a música e a harmonia, atrevo-me a atrair para mim todos os indígenas da América".

Com a música foi possível tornar os laços mais estreitos entre as comunidades indígenas 
e os padres catequizadores, estes que logo após sua chegada formaram aldeamentos que davam o nome de Missôes ou Reduçôes afim de catequizar os índios, levar a fé até eles através de cantos religiosos.

Nessa época a música ainda não era vista como uma prática educativa, seus benefícios eram puramente de ordem religiosa. Só a partir do século XVII que a música popular toma conta do Brasil. No período colonial e primeiro império as valsas, polcas, tangos e outras manifestaçóes musicais tomam destaques contribuindo para essa enorme variedade de hoje em dia, a respeito dessa diversidade estrangeiro Renato Almeida expressa em seu livro A História da Música Brasileira (1926, p.108):

Queremos dizer que, na nossa música popular, é fácil distinguir as origens rítmicas, embora não se conserve exatas e essenciais. Um mundo de influências e interferências, o clima o caldeamento do sangue, o cultivo e as condiçóes de vida de lugar a lugar, tudo isso, que a arte popular reflete, refrangendo no prisma de suas intençóes fez com que os cantares fossem variando dia por dia, contornandose, modificando-se, mas sem perder o caráter básico e definitivo do ritmo.

Aos africanos em considerável parte, devemos agradecer a formação da nossa música popular brasileira, em especial ao ritmo que enriqueceu nossa cultura musical.

Embora no século XIX e XX nossa cultura musical já fosse rica em variedades, isso ainda iria melhorar, com o fim da escravidão abriu-se novas fronteiras para imigrantes europeus afim de trabalhar nas lavouras de algodão e café, com isso trouxeram com sigo uma grande bagagem musical de sua terra natal abrilhantando ainda mais a cultura musical brasileira que ganhou a mazurca que mais tarde se torna o maxixe brasileiro e a criação do choro.

Mas ainda era pouco, assim sendo no século XX, ouve a inserção do samba no Brasil com o carnaval, se tornando o ritmo mais famoso do país. Logo com a industrialização o rádio a televisão chegamos a variedade considerável que temos hoje no Brasil.

Em relação ao ensino da música, do descobrimento ao meado do século XX não há registro que estabeleça uma relação pedagógica em seu ensino infelizmente, era usada apenas para aprender a tocar instrumentos ou com fins religiosos ou como manifestação cultural.

No ano de 1854, após um decreto real a música toma caráter pedagógico, mas a falta de professores formados era um impasse e a música serviria apenas para fins de controle de alunos e entretenimento dos mesmos. Loureiro (2003) explica que nessa fase era dada pouca ênfase aos aspectos musicais pela escola. Trabalhar questôes culturais, música como meio de interação entre as outras disciplinas, só se tornaria possível na metade do século XX com a evolução da educação infantil como instituição educativa, deixando de lado o caráter assistencialista.

\section{Música e Educaçáo Infantil}

As vivências das crianças diariamente, as descobertas que fazem, as experiências que conservam do vivenciado é que constrói seu aprendizado, sabendo disso é importante proporcionar aos mesmos ambientes ao quais, se sintam à vontade e tenham prazer em conviver nestes, com isso deve-se construir métodos aos quais vão subsidiar as mesmas a construir sozinhas ou em grupo seu conhecimento de espaço, de cultura, de mundo.

As cantigas são aliadas a esse respeito, pois possibilita as crianças até as mais tímidas a 
oportunidade de se comunicar, interagir com outras e com o ambiente, e por alguns poucos mais valiosos momentos esquecer da timidez que se entrelaça com pontos consequentes para interferir de maneira negativa na aprendizagem dessas crianças.

A harmonia musical também é muito construtora da aprendizagem quando aliada a outras disciplinas para promover aprendizagem. Por exemplo, é muito mais fácil aprender matemática quando se tem uma música para auxiliar.

A musicalização é integradora do processo de construção da formação integral do ser humano, com a música pode-se despertar a criatividade da criança, imaginação, a percepção auditiva, a coordenação motora, a memorização, socialização, a expressividade como também a noção de espaço dentre outros objetivos.

A música é incentivadora e estimuladora para o processo de aprendizagem e a imitação, a percepção, concentração, a criação que esta permite as crianças são elementos fundamentais para esse processo.

Com a musicalizaçáo temos a capacidade de trabalhar muitos aspectos favoráveis ao mesmo tempo, que com outra forma de aprendizagem talvez não fosse tão esclarecedora para as crianças como é na música, permite a abrangência do leque do saber na educação infantil muito grande e benéfico para a mesma.

Como diria Brito (2003) a criança como ser brincante que é faz-se necessário o uso de metodologias que satisfaça e estimule as mesmas de forma que essas construam conhecimentos diariamente, e a música tem essa função de propiciar movimento, mobilização nas crianças e por isso é facilitadora da construção na transformação e no desenvolvimento que induz a aprendizagem como um todo.

\section{0 processo do trabalho musical na Educaçáo Infantil}

\subsection{A música no ambiente escolar}

[...] a música é tratada como se fosse um produto pronto, que se aprende a reproduzir, e não uma linguagem cujo conhecimento se constrói (BRASIL, 1998, p. 47).

Hoje nas escolas é muito comum ver repetiçôes de músicas e de gestos prontos, algo mecanizado para ficar bonito para quem assiste, em festas comemorativas dentre outras ocasióes, muitas vezes ensaiado várias vezes para que se atinja a perfeita sincronização de movimentos, o que é cansativo e chato para as crianças, desanimador e nada interativo.

No contexto da educação infantil a música é muito usada para criação de hábitos, atitudes e também comportamentos e nada mais. Isto vem de uma longa história com a questão do trabalho da musicalização na educação, e que nos dias atuais vem sendo revista, através de pesquisas e propostas para uma melhoria na propagação da música, como algo transformador e construtor de aprendizagem intrínseca na educação infantil. Mas ainda assim à a permanência da melodia como hora de escovar os dentes, hora de lanchar, dentre outros momentos eventuais ou de comemoraçóes.

Esses meios de se trabalhar com a musicalidade na educação infantil são retrógrados tendo em vista que a música é uma fonte de estímulos para as crianças, principalmente as que 
compôem o grupo de 0 à 5 anos, é importante tornar claro que a música não tem só uma função, pois como já falado, ela compóe um leque muito grande de benefícios, esses que fazem parte também da formação de hábitos e comportamentos mas, desde de que trabalhe-se de forma criativa, estimulando e não apenas tornando-se atos mecânicos e sem objetivos.

Pode-se incorporar a educação musical como parte integrante da formação do individuo desde a infância, atendendo a vários propósitos, como a formação de hábitos atitudes e comportamentos: ao lavar as mãos antes do lanche, ao agradecer a "papai do céu" por mais um dia de estudo, ao escovar os dentes, na memorização de conteúdos, de números, de letras e etc. (BUENO, 2012, p. 55).

A sonoridade é uma ótima aliada na hora de aprender as letras, porque vai ajudar a criança na socialização das mesmas, construir outras palavras, quando se tornam participativas estas tendem a se motivarem e formar ideias e até mesmo criar cançôes próprias da maneira delas é claro.

Dessa maneira, a musicalidade é uma linguagem muito rica em todos os aspectos, é libertadora e envolvente ao mesmo tempo, desperta paixóes das mais diversas em nossas vidas, torna-nos calmos e também animados com disposição, tem o poder de transformaçáo facilitando a comunicação, a expressão e abrindo a porta principalmente para as crianças mais tímidas buscar por socialização no seu meio.

Sendo assim, com a musicalização é possível respeitar a maneira de ser de cada um, porque é fácil diversificar, não se precisa ter necessariamente uma rotina, pode-se inovar, não faltando atividades, pois o repertório para se trabalhar com o lúdico assim se torna expansivo.

Há várias formas de se trabalhar a música na escola, por exemplo, de forma lúdica e coletiva, utilizando jogos, brincadeiras de roda e confecção de instrumentos. A imaginação é uma grande aliada nesse quesito, lembrando que a musicalidade está dentro de cada pessoa. (BUENO, 2011, p. 231).

Nesse ponto devemos dar ênfase à postura do professor que fará toda diferença na hora de mediar esse conhecimento, ele é quem será o estimulador, o orientador e por isso tem que estar animado e envolvido no trabalho, ser criativo e proporcionar aos seus alunos a liberdade de criação e interpretação daquilo que li são expostos.

A música dá a possibilidade de se trabalhar todas as áreas do conhecimento: Linguística, afetiva/social, e psicomotora, estes por sua vez estão ligados de forma que não da para se trabalhar um sem que aja uma afetação do outro. Graças ao seu poder de provocar sentimentos, pensamentos, imaginação, afeto, movimento, dentro outros a música possibilita essa interação de todos os aspectos ao mesmo tempo, tornando a aprendizagem afetiva.

Todos os aspectos do desenvolvimento estão intimamente relacionados e exercem influência uns sobre os outros, a ponto de não ser possível estimular o desenvolvimento de um deles sem que, ao mesmo tempo, os outros sejam igualmente afetados. (WEIGEL,1988, p. 13).

Por isso a participação da musicalização em outras disciplinas também é importante, pois engloba todo um contexto eficaz na propagação da aprendizagem como um todo, esta que por sua vez acontece ora individualmente, ora em grupos. Porem é importante lembrar quê: $\mathrm{O}$ RCNEI (BRASIL, 1998, p.49), alerta para o uso da música também como exercício das suas funções próprias, específicas musicais. 


\subsection{A importância de confeccionar instrumentos musicais com as crianças da Educaçáo Infantil}

A diversificação de instrumentos musicais é grande o que contribui para o aumento de variedades de sons que ouvimos uns mais harmônicos, outros mais expressivos, ou seja, depende do instrumento que o produz. Tendo em vista essa variedade, deve-se usar a criatividade para a criação de instrumentos aos quais contribuirá de forma satisfatória para o aprendizado da criança. Estes podem ser feitos até mesmo de sucatas, construídos pelas próprias crianças dentro da sala de aula com a ajuda do professor, a aprendizagem assim se dará num todo sobre os mesmos, já que assim se estabelece a ligaçáo do instrumento com o som feito por ele, e ainda como ele foi criado. Um dos efeitos da música na educação infantil é justamente esse, de promover vivências na aprendizagem.

[...] para atender ao interesse da criança e em consonância com o desenvolvimento do seu pensamento, a música na pré-escola deve possibilitar vivências e descobertas, constituindo-se numa experiência concreta (WEIGEL,1988, p. 18).

Pensando nesses termos, devem oportunizar as crianças momentos que originem essas experiências e a construção de instrumentos musicais de sucata é uma boa opção, como também atividades que possibilite as mesmas manusear, tocar, explorar os instrumentos musicais.

Descobriram novos ritmos, sonoridade de cada instrumento e dentro desse contexto se trabalha também a questão da cultura, a socialização, a criticidade individual de acordo com o gosto de cada um, onde se dará a construçáo de opinióes próprias, elevando a autoestima e firmando a identidade da criança.

O primeiro contato das crianças com instrumentos musicais causa muita curiosidade, pois ela descobre que sua voz não é o único som formador de música, e pegando um gancho nessa curiosidade deve se estimular a mesma a descobrir qual instrumento ela se identifica mais, afim de uma melhor exploração do mesmo e a construção de uma sonoridade própria da criança.

O RCNEI (BRASIL, 1998, p. 69), nos afirma que: "A atividade de construção de instrumentos é de grande importância e por isso poderá justificar a organização de um momento específico na rotina, comumente denominado de oficina".

Essas "oficinas" possibilitam a criança o manuseio de objetos, oportuniza pesquisas, aumenta a criatividade, trabalha-se a coordenação motora, a socialização em grupos, favorece a concentração dentre outras funçôes extremamente importantes para construção do conhecimento.

Contudo vale ressaltar que deve haver um planejamento para esse tipo de trabalho, inspeção de tempo integral do professor, até mesmo porque alguns objetos deverão ser manipulados de forma muito cuidadosa, como tesouras e colas, dentre outros que se juntaram na confecção dos instrumentos musicais.

Acima de tudo é preciso que em cada regiáo do país este trabalho aproveite os recursos naturais, os materiais encontrados com mais facilidade e a experiência dos artesãos locais, que poderão colaborar positivamente para o desenvolvimento do trabalho com as crianças. (BRASIL, 1998, p. 69).

\subsection{Brincadeiras que auxiliam na formação da conscientizaçáo da importância da música na história do homem}

Quem nunca brincou de dança da cadeira? Ou de adoleta? Ou de ciranda quem sabe? 
Brincadeiras essas tão tradicionais que nem o tempo conseguiu apagar, nem os mais variados tipos de tecnologias foram capazes de fazer morrer, pois são especiais, algumas tem as letras das músicas modificadas de acordo com sua região, o que só favorece a beleza das brincadeiras.

$\mathrm{Na}$ escola de educação infantil o jeito mais astuto de se trabalhar é com o lúdico, pois envolve uma gama muito grande de brincadeiras capazes de trabalhar diferentes e variadas funçôes do nosso corpo ao mesmo tempo, possibilitando além da diversão aos pequeninos também o aprendizado significativo, pois favorece muito a participação dos envolvidos gerando experiências concretas, como a ciranda onde as crianças formam uma roda dão-se as mãos e cantam coreografando:

$$
\begin{aligned}
& \text { Ciranda, cirandinha } \\
& \text { Vamos todos cirandar } \\
& \text { Vamos dar a meia volta } \\
& \text { Volta e meia, vamos dar... }
\end{aligned}
$$

A música está intrinsecamente inserida nesse meio prazeroso de se aprender, seja em forma de danças, estímulos de brincadeiras ou somente cançóes para se ouvir. A música deve fazer parte do cotidiano escolar como também as brincadeiras porque são importantes para o desenvolvimento de forma integral das crianças.

Conforme Bueno, “[...] a música deve ser transmitida com alegria, vibração, através de uma metodologia lúdica e dinâmica, própria do mundo da criança”. (BUENO, 2011, p. 178). Isso nos remete que a fórmula essencial para desenvolver um trabalho criativo e de grande relevância pedagógica depende da criatividade de cada professor, pois o repertório é grande a variedade imensa de músicas e brincadeiras compatíveis com cada idade a ser trabalhada porque brincar faz parte da cultura da criança e o professor deve tirar proveito desse benefício.

A Cultura Tradicional da Infância é todo o universo de brinquedo e brincadeiras que vêm se perpetuando ao longo de séculos, passando de uma geração a outra, proporcionando convívio e interação entre as crianças. É ao mesmo tempo tradicional, popular e contemporânea, pois sofre transformaçóes se adequando a cada novo tempo, sem perder a essência. Incrivelmente ampla, abrange acalantos, brincos, histórias, advinhas, trava-línguas, quadrinhas, fórmulas de escolha, rodas, amarelinhas, jogos, pegadores, brincadeiras com bola, corda, elástico, mão, pedra e o objeto brinquedo. (SILVA apud, JORDÃO, 2012, p. 146).

O meio cultural de cada região é que vai distinguir o ritmo a ser usado em cada canção ou brincadeiras, pois exercem uma influência muito grande e deve ser respeitado pelo professor e por todos, pois é isso que nos remete a diversidade de expressóes culturais.

\section{Consideraçóes finais}

A partir da realização desse trabalho ficou mais nítido como a música foi implantada no Brasil, quais suas origens e como se tornou táo popular hoje em dia, e ainda a importância dos europeus, índios e africanos para nossa cultura

Nesse sentido, o trabalho possibilitou também a compreensão da importância da música na educação infantil, suas contribuiçôes na formação e desenvolvimento da criança, na grande diversidade de se trabalhar com a música como meio facilitador do ensino-aprendizagem. 
A fase do descobrimento, da curiosidade, descobertas se concentra na educação infantil e são essenciais para o desenvolvimento cognitivo, motor, emocional, e social e linguístico da criança e essa fase é muito propícia a ser trabalha com a música porque ela dá suporte e trabalha ao mesmo tempo todas essas áreas de forma lúdica, criativa e acima de tudo pedagógica.

Ocasionou a verificação da importância desses trabalhos serem planejados para que não se tornem apenas parte da rotina ou passa tempo, pois o bom planejamento é a alma da aula proveitosa.

A música é uma forma lúdica de se trabalhar na educação infantil, que além de prazer à criança da a ela também suporte para descobertas, para mediação de conhecimento entre professor-aluno e aluno-professor, e ainda é estimuladora de senso rítmico, audição, concentração, noção de tempo e espaço é fundamental ser trabalhada desde muito cedo na educação infantil para que se tenha futuramente sucesso no despertar de todas habilidades possíveis na criança.

\section{Referências}

ANTUNES, C. Jogos para a estimulação das inteligências múltiplas. Petrópolis: Vozes, 1999.

BRASIL, Referencial Curricular Nacional para a Educaçáo Infantil, Brasília: Mec,1998.

BRITO Teca Alencar de. Música na Educação Infantil. (propostas para a formação integral da criança). Ed. Petrópolis, 2004.

BUENO, Roberto. Pedagogia da Música-Volume 1. Jundiaí, Keyboard,

2011. Formação Integral da Criança. São Paulo, Peirópolis, 2003

ESTEVÃO, Vânia Andréia Bagatoli. A importância da música e da dança no

Desenvolvimento infantil. 2002.

GAINZA, V. HEMSY de. Estudos de psicopedagogia musical. São Paulo: Summus. 1988.

PEREIRA, Amauri Mendes. Para além do racismo e do antirracismo: A construçáo de uma cultura de consciência negra. Itajaí: Editora Casa Aberta, 2012.

SOUSA, J. V. DE; VIVALDO, L. A importância da música na Educação Infantil. P@rtes Revista Eletrônica. 2010. 